\title{
Role of duration of catheterization and length of hospital stay on the rate of catheter-related hospital-acquired urinary tract infections
}

This article was published in the following Dove Press journal:

Research and Reports in Urology

25 March 2015

Number of times this article has been viewed

\section{Hamdan Al-Hazmi}

Division of Urology, Department of Surgery, College of Medicine and King Khalid University Hospital, King Saud University, Riyadh, Saudi Arabia
Correspondence: Hamdan Al-Hazmi Department of Surgery, Division of Urology, Department of Surgery, College of Medicine and King Khalid University Hospital, King Saud University, PO Box 7805, Riyadh II472, Saudi Arabia Tel +966 II4 67। 575 ext I538

Fax+966 II 679493

Email drhamdan@ksu.edu.sa
Objective: Our aim is to prove that duration of catheterization and length of hospital stay (LOS) are associated with the rate of hospital-acquired urinary tract infections (UTI), while taking into account type of urinary catheter used, the most common organisms found, patient diagnosis on admission, associated comorbidities, age, sex, precautions that should be taken to avoid UTI, and comparison with other studies.

Methods: The study was done in a university teaching hospital with a 920-bed capacity; this hospital is a tertiary care center in Riyadh, Saudi Arabia. The study was done on 250 selected patients during the year 2010 as a retrospective descriptive study. Patients were selected as purposive sample, all of them having been exposed to urinary catheterization; hospital-acquired UTI were found in 100 patients. Data were abstracted from the archived patients' files in the medical record department using the annual infection control logbook prepared by the infection control department. The data collected were demographic information about the patients, clinical condition (diagnosis and the LOS), and possible risk factors for infection such as duration of catheterization, exposure to invasive devices or surgical procedures, and medical condition.

Results: There was a statistically significant association between the rate of UTI and duration of catheterization: seven patients had UTI out of 46 catheterized patients (15\%) at 3 days of catheterization, while 30 patients had UTI out of 44 catheterized patients $(68 \%)$ at 8 days of catheterization (median 8 days in infected patients versus 3 days in noninfected patients; $P$-value $<0.05$ ), which means that the longer the duration of catheterization, the higher the UTI rate. There was a statistically significant association between the rate of UTI and LOS: three patients had UTI out of 37 catheterized patients $(8 \%)$ at 10 days LOS, while 42 patients had UTI out of 49 catheterized patients $(85.7 \%)$ at 18 days LOS. The longer the LOS, the higher the UTI rate: LOS for each patient (median 18 days for infected patients versus 10 days for noninfected patients; $P$-value $<0.05$ ), and number of hospital-acquired catheter-related UTI (100 patients had UTI out of 250 catheterized patients, $P=0.04$ ).

Conclusion: Reduction of the duration of catheterization and LOS of the patient have a positive impact in reduction of catheter-related UTI.

Keywords: urinary catheters, catheter duration, adult

\section{Introduction}

Catheter-related (CR) hospital-acquired (HA) urinary tract infection (UTI) refers to the culture growth of $\geq 103$ colony forming units ( $\mathrm{cfu}$ )/mL of uropathogenic bacteria with the presence of signs or symptoms such as fever, or suprapubic or costovertebral angle tenderness in a patient with indwelling urethral, indwelling suprapubic, or intermittent catheterization. Usually, UTIs are classified by the site of infection (the bladder [cystitis], kidney [pyelonephritis], or urine [bacteriuria]). UTIs can be 
asymptomatic or symptomatic, which is characterized by a wide spectrum of symptoms ranging from mild irritation while voiding to bacteremia, sepsis, or even death. UTIs that occur in a normal genitourinary tract with no prior instrumentation are considered "uncomplicated", whereas "complicated" infections are diagnosed in genitourinary tracts that have structural or functional abnormalities, including instrumentation such as indwelling urethral catheters, and are frequently symptomatic. Patients with an otherwise normal genitourinary tract who have symptomatic renal infection are diagnosed as having acute uncomplicated pyelonephritis. However, reduction of the rate and duration of unnecessary catheterization may have an impact in reduction of HA CR UTI. ${ }^{1}$

The objectives and aims of our study depend upon the hypothesis and aim to prove that duration of catheterization and length of hospital stay are associated with the rate of HA UTIs. Strict adherence to appropriate infection control procedures is necessary if the incidence and sequels of $\mathrm{CR}$ infections are to be reduced. ${ }^{2}$

\section{Materials and methods}

The study was done during the year 2010 in a university teaching hospital with a 920-bed capacity; this hospital is a tertiary care center, related to King Saud Medical City, in Riyadh, Saudi Arabia. The study was held as retrospective descriptive study. Patients were selected as purposive total sample. The hospital has an established infection control system that performs surveillance continuously on a regular basis every 3 weeks of surgical services due to high rates of hospital-related infections, following National Nosocomial Infection Surveillance guidelines. The index of the risk of infections for each patient was based on the severity of illness (as measured by the Anesthesiology Score of America), and the type and duration of the procedure. Also, continuous active surveillance was done for patients with estimated prolonged length of stay (LOS), such as terminal disease patients, cancer patients, and patients with obstructive uropathy, due to high risk and susceptibility of infection due to low immunity and retained excretions, and we selected cases of those most susceptible and vulnerable to UTI. To diagnose a patient of our population that they had developed UTI they should have met certain criteria and this was defined as a patient hospitalized in the medical or surgical ward in 2010 with principle diagnosis other than UTI; who developed symptoms or signs such as fever, or suprapubic or costovertebral angle tenderness, after installment of indwelling urethral, indwelling suprapubic, or intermittent catheterization; and for whom either routine culture of urine or urine culture done before lodging of a new catheter (after removal of the old one) identifies growth of $\geq 103 \mathrm{cfu} / \mathrm{mL}$ of uropathogenic bacteria.

There were no specific exclusion criteria based on age, sex, or any medical or demographic characteristics for the patient. Fifteen articles mentioned intervention outcomes for catheter associated UTI rates. ${ }^{1-15}$ Follow-up time varied across studies for evaluation of catheter associated UTI development, and if any admitted patient developed any signs or symptoms suspicious of infections, they were sent to the microbiology lab to be examined. Type of infection for each patient was determined according to preset clear case definitions approved by and documented in the infection control guidelines of the hospital. Case definition is based on the clinical picture and the bacteriological examination. Confirmed types of infections were verified as previously stated, and the cases were then recorded in the infection control logbook. The medical identification number of the patients selected from the infection control logbook was used to retrieve the archived files of the patients. The items collected in a data collection sheet were sociodemographic information, clinical condition of the patients (diagnosis, length of hospital stay, duration of catheterization), medical history of the patients, exposure to invasive devices like urinary catheter, and period of catheterization.

\section{Bacteriological examination}

Specimens were collected using complete aseptic techniques, each according to the type of the infection to be examined.

In our study, we concentrated on length of hospital stay (which was calculated in hospital bed days) and duration of catheterization in the patient. Both were considered as comorbidity risk factors and predisposing factors contributing to acquirement of UTI.

Data was entered in Excel spreadsheet, and then transferred to SPSS version 14 for data analysis. Simple frequency tables and cross tabulation were generated to describe the data. Chi-square and $t$-test were used to compare qualitative and quantitative data, respectively. Significance was set at 0.05 levels. Data was coded and patient names or identity did not appear in any of the data collection forms or during statistical analysis. Approvals and formal authentications were acquired from the ethics and patient rights committee to whom proposal and detailed research methodology were presented and agreed upon, according to the Declaration of Helsinki (Finland) roles and policies. No consent was taken as there was no patient contact, there was no financial 
support from any funding body, and there were no conflicts of interest.

\section{Results}

The study was done on 250 selected patients, all of them having been exposed to urinary catheterization. Two hundred and fifty patients were chosen by purposive nonprobability sampling according to certain criteria, where 100 patients (40\%) had HA UTI. An infection control survey in 2010 for those patients vulnerable to infection proved that there was no UTI at the time of admission. All of them underwent urinary catheterization by soft rubber self-retaining Foley's catheters, due to bladder outlet obstruction in 135 patients (54\%), the need for accurate measurements of urinary output in 67 patients $(27 \%)$, or the management of incontinence in 48 patients (19\%). Duration of catheterization was measured by the period of catheterization from lodging of the catheter until the time of catheter change, provided that urine culture was performed (which is supposed to be negative to exclude UTI) before the next catheter installation.

The mean age of patients was $56.21 \pm 24.36$ years, 65 patients $(26 \%)$ ranged between 32 years and 53 years, and 15 of these patients had UTI (23\%). Ninety-seven patients (39\%) ranged between 55 years and 62 years, and 40 of them had UTI (41\%). Eighty-eight patients (35\%) were older than 62 years of age, and 45 of them had UTI (51.8\%). Of the patients between 55 and 62 years of age who also had controlled diabetes, $17.5 \%$ had UTI. Of the patients aged older than 62 years who also had controlled diabetes, 32\% had UTI; and of the patients aged older than 62 years who also had controlled hypertension, none of them had UTI. However, none of the 250 patients were taking antibiotics except for those who underwent operative procedures (31\%) who were taking preoperative prophylactic doses of intravenous antibiotics. None of our patients were admitted to intensive care unit or were immunocompromised.
Patients were classified according to final medical diagnosis into six groups. Prostate gland disease was diagnosed in 115 patients (46\%), all of whom were catheterized, and was divided in to two groups: A) benign prostatic hyperplasia (70 patients, $50 \%$ of whom developed UTI); and B) prostate cancer (45 patients, $21 \%$ of whom had UTI). Urinary system disease was diagnosed in 68 patients (27\%), all of whom were catheterized, and was divided in to two groups: C) urinary incontinence ( 48 patients, $14 \%$ of whom developed UTI); and D) chronic urinary retention due to bladder outlet obstruction by either bladder cancer, fibrosis, or stone (20 patients, $15 \%$ of whom had UTI). Gastrointestinal disease E) was diagnosed in 37 patients with cancer colon $(20 \%)$, all of whom were catheterized, and 23 patients had UTI (62\%), and liver disease with hepatic carcinoma F) was diagnosed in 30 patients (7\%), all of whom were catheterized, and 23 patients had UTI (77\%). All patients were admitted to hospital medical and surgical wards for a variable period of time; however, all of them had a good general condition in the early stage of disease, except for those with liver and colon cancer who were terminally ill and needed measurements of urinary output (Tables 1 and 2).

Bacteriological microscopic examination of urine samples and urine culture showed that 100 patients had urinary tract infections that resulted in growth of multiple organisms as follows: 40\% Escherichia coli, 8\% Klebsiella pneumoniae, 7\% Proteus saprophyticus, 6.5\% Providencia species, 7\% Pseudomonas aeruginosa, 7\% Enterobacter saprophyticus, 6\% Serratia species, 5.5\% Enterococcus faecalis, 5\% Staphylococcus saprophyticus, 4\% Staphylococcus aureus, 2\% Salmonella species, and 2\% Candida albicans (Figure 1).

The rate of UTIs that are CR differs from disease to disease. Fifty percent of benign prostatic hyperplasia patients developed UTI while $21 \%$ of prostate cancer patients had UTI. Fourteen percent of urinary incontinence patients developed UTI, and $15 \%$ of patients with chronic urinary

Table I Demographic characteristics of selected patients according to diagnosis, sex, and percentage of infected patients

\begin{tabular}{|c|c|c|c|c|c|}
\hline \multirow{2}{*}{$\begin{array}{l}\text { Patients classified into six groups } \\
\text { according to principle diagnosis } \\
\text { with which they were admitted }\end{array}$} & \multirow[t]{2}{*}{ Indication of catheter } & \multirow{2}{*}{$\begin{array}{l}\text { Number of } \\
\text { patients }\end{array}$} & \multirow{2}{*}{$\begin{array}{l}\text { Number } \\
\text { (percentage) of } \\
\text { infected patients }\end{array}$} & \multicolumn{2}{|l|}{ Sex } \\
\hline & & & & Male & Female \\
\hline Group A (benign prostatic hyperplasia) & Bladder outlet obstruction & 70 & $35(50 \%)$ & $100 \%$ & $0 \%$ \\
\hline Group B (prostate cancer) & & 45 & $9(21 \%)$ & $100 \%$ & $0 \%$ \\
\hline Group C (urinary incontinence) & Urinary incontinence & 48 & 7 (I4\%) & $22 \%$ & $78 \%$ \\
\hline Group D (bladder outlet obstruction) & Bladder outlet obstruction & 20 & $3(15 \%)$ & $53 \%$ & $47 \%$ \\
\hline Group E (colon cancer) & Measurement of urine output & 37 & $23(62 \%)$ & $33 \%$ & $67 \%$ \\
\hline Group F (hepatic carcinoma) & & 30 & $23(77 \%)$ & $47 \%$ & $53 \%$ \\
\hline Total & & $\begin{array}{l}250, \text { all of whom } \\
\text { were catheterized }\end{array}$ & $100(40 \%)$ & $43.6 \%$ & $56.4 \%$ \\
\hline
\end{tabular}


Table 2 Association between age and comorbidities in rate of catheter-related hospital-acquired UTI

\begin{tabular}{|c|c|c|c|c|c|c|c|c|c|c|}
\hline \multirow{3}{*}{$\begin{array}{l}\text { Classification of } \\
\text { patients according } \\
\text { to age }\end{array}$} & \multirow{3}{*}{$\begin{array}{l}\text { Number } \\
\text { (percentage) } \\
\text { of patients }\end{array}$} & \multirow{3}{*}{$\begin{array}{l}\text { Number } \\
\text { (percentage) } \\
\text { of infections }\end{array}$} & \multicolumn{8}{|c|}{ Comorbidities } \\
\hline & & & \multicolumn{2}{|l|}{ Diabetes } & \multicolumn{2}{|c|}{ Hypertension } & \multicolumn{2}{|c|}{ Operations } & \multicolumn{2}{|c|}{ Antibiotics } \\
\hline & & & No UTI & UTI & No UTI & UTI & No UTI & $\overline{\text { UTI }}$ & No UTI & UTI \\
\hline $32-53$ years & $65(26 \%)$ & $15(23 \%)$ & 0 & 0 & 0 & 0 & 6 & 1 & 6 & 1 \\
\hline $55-62$ years & 97 (39\%) & $40(41.2 \%)$ & 6 & 17 & 0 & 0 & 16 & 5 & 16 & 5 \\
\hline Above 62 years & $88(35 \%)$ & $45(51.8 \%)$ & 7 & 28 & 5 & 0 & 31 & 17 & 31 & 17 \\
\hline Total & & & 13 & 45 & 5 & 0 & 53 & 23 & 53 & 23 \\
\hline Total & $250(100 \%)$ & $100(40 \%)$ & 58 & & 5 & & 76 & & 76 & \\
\hline \multicolumn{3}{|c|}{ RR, chi-square test, $P$-value } & \multicolumn{2}{|c|}{$\begin{array}{l}\mathrm{RR}=\mathrm{I} . \mathrm{I}, r^{2}=0.74539 \\
P \text {-value }=0.02\end{array}$} & \multicolumn{6}{|c|}{$\begin{array}{l}\mathrm{RR}=1.3, r^{2}=0.811634, \mathrm{RR}=1.3, r^{2}=0.985634, P \text {-value }=0.04 \\
P \text {-value }=0.03\end{array}$} \\
\hline
\end{tabular}

Abbreviations: RR, relative risk; UTI, urinary tract infection.

retention due to bladder outlet obstruction (from bladder cancer, fibrosis, or stone) had UTI. Genitourinary disease patients were associated with the highest rate of UTIs: 54 patients out of $100(54 \%)(P$-value $<0.001)$. Sixty-two percent of patients with colon cancer had UTIs, and 77\% of hepatic carcinoma patients had UTI; those with liver and colon cancer were terminally ill, and this was the diagnosis with the highest rate of UTIs ( $P$-value $<0.05$ ).

Sixty-eight percent of patients who had UTIs suffered from prolonged catheter duration ( 8 days), $32 \%$ of the patients who did not have UTIs also suffered from prolonged catheter duration ( 8 days), and the rest of the patients who had UTIs (70 patients) were catheterized for a period of 3-6 days. One hundred and fifty patients had no UTI; however, all of them were catheterized for a period $<3$ days. There was a statistically significant association between the rate of UTI and duration of catheterization. Seven patients had UTIs out of 46 patients catheterized (15\%) for a period of 3 days (median 8 days in infected patients versus 3 days in noninfected patients; $P$-value $<0.05$ ) (Table 3 ). There was a statistically significant association between the rate of UTI and length of hospital stay. Three patients had UTIs out of 37 patients catheterized ( $8 \%$ ) at 10 days LOS, and 42 patients had UTI out of 49 patients catheterized (85.5\%) at 18 days LOS. Length of hospital stay for each patient (median 18 days for infected patients versus 10 days for noninfected patients; $P$-value $<0.05$ ) (Table 4 ) and number of HA CR UTIs (100 patients had UTI out of 250 catheterized patients, $P=0.04$ ).

\section{Discussion}

UTIs account for approximately $40 \%$ of all HA infections annually, with $80 \%$ of these HA UTIs attributable to indwelling urethral catheters. It is well established that the duration of catheterization is directly related to risk for

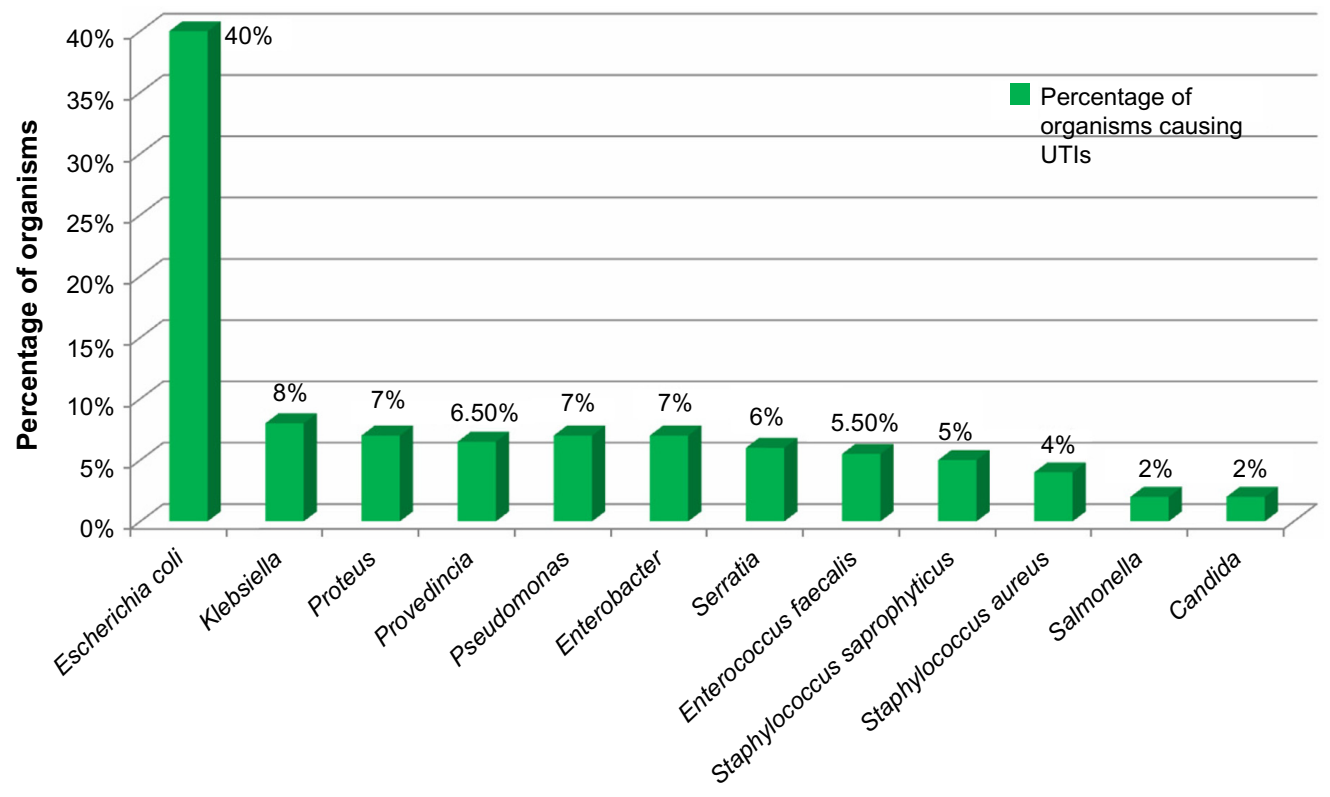

Figure I Percentage of organisms causing UTIs. Abbreviation: UTIs, urinary tract infections. 
Table 3 Statistically significant reduction in rate of CR UTI in relation to the duration of catheterization (median 8 days in infected patients versus 3 days in noninfected patients; $P<0.05$ )

\begin{tabular}{|c|c|c|c|c|c|c|c|c|c|}
\hline \multirow{3}{*}{$\begin{array}{l}\text { Patients classified into } \\
\text { six groups according to } \\
\text { principle diagnosis with } \\
\text { which they were admitted }\end{array}$} & \multirow{3}{*}{$\begin{array}{l}\text { Patient } \\
\text { had urinary } \\
\text { catheter }\end{array}$} & \multirow{3}{*}{$\begin{array}{l}\text { Sex } \\
\% \\
\text { Males }\end{array}$} & \multirow{3}{*}{$\begin{array}{l}\begin{array}{l}\text { Age } \\
(\text { mean })\end{array} \\
\text { Years }\end{array}$} & \multirow{3}{*}{$\begin{array}{l}\text { Duration of } \\
\text { catheterization } \\
\text { in days } \\
\text { (median) }\end{array}$} & \multicolumn{2}{|l|}{ CR UTI } & \multirow{3}{*}{$\begin{array}{l}\text { Unpaired } \\
\text { student's } \\
\text { t-test }\end{array}$} & \multirow{3}{*}{$\begin{array}{l}\text { Chi-square } \\
\chi^{2}\end{array}$} & \multirow[t]{3}{*}{$P$-value } \\
\hline & & & & & Percent & $\mathbf{N}$ & & & \\
\hline & & & & & & & & & \\
\hline $\begin{array}{l}\text { Group A (benign prostatic } \\
\text { hyperplasia) }\end{array}$ & 44 & $100 \%$ & 47 & 8 & $68 \%$ & 30 & $0.000|5995|$ & 0.98769558 & 0.01423 \\
\hline Group B (prostate cancer) & 46 & $100 \%$ & 36 & 3 & $15 \%$ & 7 & & 0.58547998 & 0.01634 \\
\hline Group C (urinary incontinence) & 41 & $56 \%$ & 42 & 6 & $36.5 \%$ & 15 & & 0.76564967 & 0.02245 \\
\hline $\begin{array}{l}\text { Group D (bladder outlet } \\
\text { obstruction) }\end{array}$ & 48 & $45 \%$ & 55 & 5 & $33 \%$ & 16 & & 0.98648597 & 0.01456 \\
\hline Group E (colon cancer) & 31 & $39 \%$ & 49 & 4 & $39 \%$ & 12 & & 0.57687960 & 0.03867 \\
\hline Group F (hepatic carcinoma) & 40 & $41 \%$ & 50 & 6 & $50 \%$ & 20 & & 0.89598694 & 0.01578 \\
\hline Total & 250 & & & & & 100 & & & \\
\hline
\end{tabular}

Abbreviations: CR, catheter-related; UTI, urinary tract infection.

developing a UTI. With a catheter in place, the daily risk of developing a UTI ranges from 3\% to $7 \%$. In our study, $56.4 \%$ of the hospital infection episodes were related to female patients; however, males are more responsive to UTIs, whereas females are four times more responsive to noninfectious inflammation and to autoinflammatory diseases. $^{3}$

The mean age of the patients was $56.21 \pm 15.36$ years, which shows that most of the infected patients were relatively old. Twenty-three percent of patients who were between 32 years and 53 years old had UTIs, while $41 \%$ of patients who were between 55 years and 62 years old had UTIs, and $51.8 \%$ of patients above 62 years old had UTIs, which means that the old-age patients were more susceptible to UTIs than young patients (relative risk $[\mathrm{RR}]=1.4, P$-value $<0.003$ ). Age is a risk factor for infections, especially extremes of age.$^{4}$ Very old and very young patients (premature and neonates) are considered the vulnerable group and are the most susceptible to immunity system dysfunction. ${ }^{5}$
Seventy-seven point five percent of diabetic patients had UTIs, while none of the hypertensive patients developed UTI. Thirty percent of patients who underwent operations and took preoperative prophylactic antibiotics had UTI, which means that diabetes is a risk factor and is associated with high rate of UTI, while neither hypertension nor operative procedures were associated with CR HA UTI; significance tests were as follows: $\mathrm{RR}=1.1, r^{2}=0.74539, P$-value $=0.02$; $\mathrm{RR}=1.3, r^{2}=0.811634, P$-value $=0.03 ; \mathrm{RR}=1.3, r^{2}=0.985634$, $P$-value $=0.04$, for diabetes, hypertension, and operative procedures, respectively. Diabetes, hypertension, and operations have been discussed in detail as risk factors for infections, especially in the research done in April 1981 at New England Deaconess Hospital, Boston, Massachusetts, which studied 136 urinary tract infections during 1,474 indwelling bladder catheterizations. There was a strong belief that persons with diabetes are more susceptible to UTI than are persons without diabetes. Multiple logistic regression analysis identified nine factors that were significantly associated with acquisition of

Table 4 Statistically significant reduction in rate of CR UTI in relation to the length of hospital stay for each patient with a urinary catheter (median 18 days in infected patients versus 10 days in noninfected patients; $P$-value $<0.05$ )

\begin{tabular}{|c|c|c|c|c|c|c|c|c|c|}
\hline \multirow{2}{*}{$\begin{array}{l}\text { Patients classified into } \\
\text { six groups according to } \\
\text { principle diagnosis with } \\
\text { which they were admitted }\end{array}$} & \multirow{2}{*}{$\begin{array}{l}\text { Patient } \\
\text { had urinary } \\
\text { catheter }\end{array}$} & \multirow{2}{*}{$\begin{array}{l}\text { Sex } \\
\% \\
\text { Males }\end{array}$} & \multirow{2}{*}{$\begin{array}{l}\begin{array}{l}\text { Age } \\
\text { (mean) }\end{array} \\
\text { Years }\end{array}$} & \multirow{2}{*}{$\begin{array}{l}\text { Length of } \\
\text { stay in days } \\
\text { (median) }\end{array}$} & \multicolumn{2}{|l|}{ CR UTI } & \multirow{2}{*}{$\begin{array}{l}\text { Unpaired } \\
\text { student's } \\
\text { t-test }\end{array}$} & \multirow{2}{*}{$\begin{array}{l}\text { Chi-square } \\
\chi^{2}\end{array}$} & \multirow[t]{2}{*}{$P$-value } \\
\hline & & & & & Percent & $\mathbf{N}$ & & & \\
\hline $\begin{array}{l}\text { Group A (benign prostatic } \\
\text { hyperplasia) }\end{array}$ & 49 & $100 \%$ & 50 & 18 & $85.7 \%$ & 42 & 0.027741735 & 0.9879886987 & 0.01789 \\
\hline Group B (prostate cancer) & 32 & $100 \%$ & 49 & 12 & $53 \%$ & 17 & & 0.8987098796 & 0.04654 \\
\hline $\begin{array}{l}\text { Group C (urinary } \\
\text { incontinence) }\end{array}$ & 37 & $60 \%$ & 55 & 10 & $8 \%$ & 3 & & 0.9870989877 & 0.02234 \\
\hline $\begin{array}{l}\text { Group D (bladder } \\
\text { outlet obstruction) }\end{array}$ & 45 & $49 \%$ & 42 & 14 & $31 \%$ & 14 & & 0.98670987078 & 0.03953 \\
\hline Group E (colon cancer) & 47 & $43 \%$ & 36 & 13 & $21 \%$ & 10 & & 0.7685980090 & 0.05368 \\
\hline Group F (hepatic carcinoma) & 40 & $45 \%$ & 47 & 15 & $31 \%$ & 14 & & 0.987969860 & 0.05432 \\
\hline Total & 150 & & & & & 78 & & & \\
\hline
\end{tabular}

Abbreviations: CR, catheter-related; UTI, urinary tract infection. 
infection: duration of catheterization and diabetes are two of them. ${ }^{6}$

Fifteen percent of patients with chronic urinary retention due to bladder outlet obstruction by either bladder cancer, fibrosis, or stone had UTI; and genitourinary disease patients were associated with the highest rate of UTIs (54 patients out of 100 [54\%]; $P$-value $<0.001)$. Sixty-two percent of patients with colon cancer had UTIs and $77 \%$ of hepatic carcinoma patients had UTI; those with liver and colon cancer were terminally ill, and this was the diagnosis with the highest rate of UTIs ( $P$-value $<0.05)$. There is a strong relation between benign prostatic hyperplasia and UTIs. Liver disease patients, especially those with cirrhosis, have altered immune defenses and are considered immune-compromised individuals. Changes in gut motility, mucosal defense, and microflora allow for translocation of enteric bacteria into mesenteric lymph nodes and the blood stream. Additionally, the cirrhotic liver is ineffective at clearing bacteria and associated endotoxins from the blood, thus allowing for seeding of the sterile peritoneal fluid. Thus, hospitalized cirrhotic patients, particularly those with gastrointestinal hemorrhage, are at high risk of developing bacterial infections.

Gram-negative bacilli were the most common organisms $(60 \%)$ found in our study, followed by gram-positive cocci $(36 \%)$ and then fungi (4\%). The same findings were detected in a national study which revealed that $E$. coli remains the predominant uropathogen $(80 \%)$ isolated in acute community-acquired uncomplicated infections, followed by S. saprophyticus (10\%-15\%), Klebsiella, Enterobacter, and Proteus spp. ${ }^{7}$

Prolonged hospitalization will not only act as a risk factor for the development of nosocomial infections, but it also increases the incidence of infection by multiple drug resistance organisms. Our results agree with other studies that concluded that prostate gland diseases, especially benign prostatic hyperplasia, can produce obstruction in the urinary tract and increase the risk for community-acquired UTI. ${ }^{8}$

As for urinary system disease patients, especially those with renal failure, our results showed a higher proportion of community infection than HA infections, and the same was also concluded in a study that identified a relationship between developing community-acquired methicillinresistant $S$. aureus blood stream infection and renal insufficiency $(P=0.041)$. However, another study concluded that sepsis and HA infection are more common with chronic renal failure. ${ }^{9}$

CR UTI occurs when urethral catheters inoculate organisms in the bladder and cause colonization due to providing a medium for bacterial adhesion and mucosal irritation. Urinary catheter is the most important risk factor for bacteriuria. In our study, there was a statistically significant association between duration of catheterization (median 8 days in infected patients versus 3 days in noninfected patients; $P$-value $<0.05$ ), length of hospital stay for each patient (median 18 days in infected patients versus 10 days in noninfected patients; $P$-value $<0.05$ ), and number of HA CR UTIs ( 100 cases versus 250 cases; $P=0.04$ ). This finding was revealed in another study done in June 2013 in the Academic Medical Center, Amsterdam, the Netherlands, where duration of catheterization, rate of unnecessary catheterization, length of hospital stay were reduced, and this in turn reduce the CA UTI rate. ${ }^{10}$

Sixty-eight percent of patients who had UTI suffered from a prolonged catheter duration ( 8 days), $32 \%$ of patients who did not have UTIs also suffered from a prolonged catheter duration ( 8 days), and the rest of patients who had UTI (70 patients) were catheterized for a period of 3-6 days. One hundred and fifty patients had no UTI; however, all of them were catheterized for a period of $<3$ days. There was a statistically significant association between the rate of UTI and duration of catheterization. Seven patients had UTI out of 46 patients catheterized (15\%) for a period of days, and 30 patients had UTIs out of 44 patients catheterized (68\%) for a period of 8 days (median 8 days in infected patients versus 3 days in noninfected patients; $P$-value $<0.05$ ) (Table 3 ), which means that the longer the duration of catheterization, the higher the UTI rate. Prolonged catheterization was the most important, potentially modified risk factor identified in many studies. ${ }^{11}$

There was a statistically significant association between the rate of UTI and length of hospital stay. Three patients had UTIs out of 37 patients catheterized ( $8 \%$ ) at 10 days LOS, and 42 patients had UTI out of 49 patients catheterized $(85.5 \%)$ at 18 days LOS. The longer the LOS, the higher the UTI rate: LOS for each patient (median 18 days for infected patients versus 10 days for noninfected patients; $P$-value, 0.05$)$, and number of hospital-acquired catheter-related UTI (100 cases versus 250 cases, $P=0.04$ ), Fewer days of catheterization and hospitalization were associated with fewer CR UTIs. Foley catheter-associated UTIs were evaluated in a case-matched and controlled study showing the rate of nosocomial UTIs among patients increased when the LOS increased by average of 2.4 days more than the expected length of stay for those patients $(P=0.017){ }^{12}$

$E$. coli is the most common organism involved in HA infections, with a rate of $40 \%$. Pseudomonas, Enterococcus, 
S. aureus, coagulase-negative Staphylococcus spp., Enterobacter spp., and yeast are known to cause infection. Proteus and Pseudomonas are the most commonly associated with biofilm growth on catheters. For either short- or longterm catheters, the infection rate is about $5 \%$ per day. ${ }^{13}$ In our study, a total of eleven organisms were detected in all episodes of infections causing UTIs. E. coli was responsible for $40 \%$ of UTI. Risk of bacteriuria was estimated as $5 \%$ for each day of catheterization. The longer the catheter remains, the higher the risk of infection. The need for continuing catheterization should be reviewed daily and the catheter removed as soon as possible. ${ }^{14}$

\section{Conclusion}

Reduction of the duration of catheterization and LOS of the patient have a positive impact on reduction of CR UTIs. The following are recommendations for reducing rates of CR UTIs:

- Use an external catheter (condom) instead of a urinary catheter if clinically appropriate ${ }^{15}$

- Use urinals for micturition once the patient is able $e^{16}$

- Remove urinary catheter once it is no longer required ${ }^{17}$

- Ensure short-term indwelling catheters

- Review the need for long-term catheters ${ }^{18}$

- Catheters duration should not exceed 3-8 days

- Early patient mobilization to avoid prolonged LOS

- Use of closed drainage system catheter to decrease CR UTI. ${ }^{19}$

\section{Acknowledgments}

Great thanks to Dr Ahmed M Elmalky, Quality Coordinator of Hospital Morbidity and Mortality Review committee; and to MPH, CPHQ, DTQM, DHQ, and MBBCH, who assisted me in completing this work.

\section{Disclosure}

The author reports no conflicts of interest in this work.

\section{References}

1. Gonzalez CM, Schaeffer AJ. Treatment of urinary tract infection: what's old, what's new, and what works. World J Urol. 1999;17(6):372-382.
2. Engel JD, Schaeffer AJ. Evaluation of and antimicrobial therapy for recurrent urinary tract infections in women. Urol Clin North Am. 1998;25(4):685-701.

3. Edmond MB, Wallace SE, McClish DK, Pfaller MA, Jones RN, Wenzel RP. Nosocomial bloodstream infections in United States hospitals: a three-year analysis. Clin Infect Dis. 1999;29(2):239-244.

4. Platt R, Polk BF, Murdock B, Rosner B. Risk factors for nosocomial urinary tract infection. Am J Epidemiol. 1986;124(6):977-985.

5. Ronald A. The etiology of urinary tract infection: traditional and emerging pathogens. Am J Med. 2002;113 Suppl 1A:14S-19S.

6. Nermin HI, Tarek AA. Frequency of Bacterial and Fungal Infections of Urinary Tract Catheterization at Cairo University Burn Center. Egyptian Journal of Medical Microbiology. 2008;42(11):5337-5340.

7. Wu CJ, Lee HC, Lee NY. Predominance of Gram-negative bacilli and increasing antimicrobial resistance in nosocomial bloodstream infections at a university hospital in southern Taiwan, 1996-2003. J Microbiol Immunol Infect. 2006;39:135-143.

8. Janzen J, Buurman BM, Spanjaard L, de Reijke TM, Goossens A, Geerlings SE. Reduction of unnecessary use of indwelling urinary catheters. BMJ Qual Saf. 2013;22(12):984-988.

9. Jain P, Parada JP, David A, Smith LG. Overuse of the indwelling urinary tract catheter in hospitalized medical patients. Arch Intern Med. 1995; 155:1425-1429.

10. Leone $\mathrm{M}$, Albanèse $\mathrm{J}$, Garnier $\mathrm{F}$, et al. Catheter-associated urinary tract infections in surgical patients: a controlled study on the excess morbidity and costs. Nosocomial bloodstream infections and clinical sepsis. Emerg Infect Dis. 2004;10(1):78-81.

11. Maki DG, Knasinski V, Tambyah PA. Risk factors for catheter associated urinary tract infection: a prospective study showing the minimal effects of catheter care violations on the risk of CAUTI. Infect Control Hosp Epidemiol. 2000;21:165.

12. Hooton TM1, Bradley SF, Cardenas DD, et al. Diagnosis, prevention, and treatment of catheter-associated urinary tract infection in adults: 2009 International Clinical Practice Guidelines from the Infectious Diseases Society of America. Clin Infect Dis. 2010;50(5): 625-663.

13. Katz S, Downs TD, Cash HR, Grotz RC. Progress in development of the index of ADL. Gerontologist. 1970;10(1):20-30.

14. Mauro MA, Jaques PF. Radiologic placement of long-term central venous catheters: a review. J Vasc Interv Radiol. 1993;4(1):127-137.

15. Pinn S. Preventing catheter-related urinary tract infections: a clinical governance imperative. J Infect Prev. 2002;3(4):22-24.

16. Bjork DT, Pelletier LL, Tight RR. Urinary tract infections with antibiotic resistant organisms in catheterized nursing home patients. Infect Control. 1984;5:173-176.

17. Long SS, Pickering LK, Prober CG, editors. Principles and practice of pediatric infectious disease. 2nd ed. Philadelphia: Churchill Livingstone; 2003.

18. Darouiche RO, Smith JA Jr, Hanna H. Efficacy of antimicrobialimpregnated bladder catheters in reducing catheter-associated bacteriuria: a prospective, randomized, multicenter clinical trial. Urology. 1999;54:976-981.

19. Maki DG, Tambaya Pa. Engineering out the risk of infection with urinary catheters. Emerg Infect Dis. 2001;7(2):342-347.

\section{Dovepress}

\section{Publish your work in this journal}

Research and Reports in Urology is an international, peer-reviewed, open access journal publishing original research, reports, editorials, reviews and commentaries on all aspects of adult and pediatric urology in the clinic and laboratory including the following topics: Pathology, pathophysiology of urological disease; Investigation and treatment of urological disease; Pharmacology of drugs used for the treatment of urological disease. The manuscript management system is completely online and includes a very quick and fair peer-review system, which is all easy to use. Visit http://www.dovepress.com/testimonials.php to read real quotes from published authors. 